\title{
Mediation in Russia: Coming to Terms with Mediation Terminology
}

\section{Alina Gennagyevna Chernyshenko}

Elena Ivanovna Kobysheva

\author{
Pyatigorsk State Linguistic University, Stavropol region, 357532, Pyatigorsk, Kalinina avenue, 9
}

\section{Doi:10.5901/mjss.2015.v6n6p302}

\section{Abstract}

\begin{abstract}
Mediation was introduced in Russia in 2010 but its implementation is still hampered by controversies over the use of mediation terminology (MT) borrowed from English. This study presents the results of a joint research initiated by a group of linguists and specialists developing legal standards for mediation in Russia to bring into the foreground the study of mediation terminology and to suggest directions for its systematization. The research uses structural and semantic analysis building a model of source language terminology (English) based on the terminological evidence of 2263 units to elaborate standards which could be applied to Russian MT. Besides, the results of the Nuclear-Peripheral analysis (that ensures translation equivalence by preserving nuclear area of semantics in both languages) laid the basis for MT Translation Project that suggested strategies for translating the collected terms into Russian.
\end{abstract}

Keywords: mediation terminology, systematization, translation strategies.

\section{Introduction}

In 2010 the State Duma implemented a "Federal law on alternative procedure of dispute resolution with participation of a mediator" in order to establish a mediation program in Russia. However, effective application of mediation is hampered by many factors such as a shortage of trained specialists, poor management etc. But one the most significant problems is little public awareness of the essence of mediation procedures (Kobysheva and Golovchenko, 2012). People do not trust mediation primarily because they do not understand the principles and advantages of out-of-court settlement. As a result, most of the cases which can be potentially mediated are being settled in courts. It minimizes the effectiveness of the law that introduced mediation in Russia in response to the demand of unloading courts from excessive numbers of civil (noncriminal) cases.

Russian practitioners emphasize that one of the obstacles for popularization of mediation is its confusing terminology. Over the last few years a lot of printed materials on mediation were issued in Russia. However, many mediators noted frequent inconsistencies concerning translation of mediation terminology (MT). It should be emphasized that today there are no dictionaries of mediation terminology except for a little number of very short glossaries which only give explanations to some basic concepts. Many mediation associations (e.g. PMA, NADRAC) which work out standards for mediation, also express concerns about controversies over the use of mediation terms as they create doubt about legal rights and aggravate negotiations between parties.

At the moment consistency of MT at the theoretical level is difficult to achieve since, in fact, there is no fixed terminological system of mediation, and therefore, both Russian and foreign specialists do not have a common linguistic ground (Clark and Brennan, 1991) for effective communication. The absence of unified terminology impedes not only the experience exchange between experts but also training of new mediators and public involvement in the process. In this respect, content harmonization within English MT is seen as the key step to systematization of this relatively new and rapidly growing terminology at the international level. Systematization of English MT at structural and semantic levels will lay basis for elaboration of unification principles and eliminate discords within Russian MT. Besides, consistent standards developed for source language terminology (which is English MT) will shed some light upon what strategies should be applied while translating English MT into Russian. A clearer understanding of how mediation terms are formed, used and what their core semantics is presented by will assist the work of translators in correcting inconsistencies within Russian MT.

This paper presents the results of a joint research initiated by a group of linguists and specialists developing legal standards for mediation in Russia to bring into the foreground the study of MT and suggest directions for its systematization. The focus of this study on the analysis of structural and semantic features of MT is, in the first place, due 
to the lack of an in-depth study of any linguistic aspects of this terminology.

\section{Theoretical Background}

\subsection{Literature review}

Modern Russian LSP communication greatly depends upon terminologies that were first established in professional and scientific English. From recent publications on terminology we know that systematization of a translated subject field terminology (SFT) in a particular language is based on the understanding of how this language "behaves in the processes of borrowings." (Steurs, 2004). But a research of this kind should begin with a study of how terms of the chosen domain come into existence in the source language (SL). Moreover, consistent use of terms in developing specialist vocabularies depends upon standards established in already developed terminological systems which are therefore a "fruitful area of joint research" (Rogers, 2004).

In this respect, systematization of Russian MT poses challenges to researchers since the source-language terminology (English) is in constant development and there are still no directions on how to define the demarcation line between English MT and other related terminologies. The first initiative aimed at solving this problem was carried out in 2002 by National Alternative Dispute Resolution Advisory Council (NADRAC) that undertook a study to stimulate discussion on MT and seek information about how terms are being used in mediation (NADRAC, 2002). The research discovered many definition inconsistencies and stressed the relevance of linguistic analysis in MT systematization. Thus, term-formation principles as well as structural and motivational models must be considered not in isolation but as backup tools for investigating ways of "approaching special knowledge" (Humbley, 2009) in different languages.

Many terminologists (Høy, 2000; Humbley, 2009 etc.) emphasized the importance of comparative researches into patterns of term formation in Russian and English terminologies as a precondition for theorizing the question. Previous research on term formation that can be called "purely descriptive" provided 2 main typological models for terminology at a structural level. Both models may be subjected to criticism but some of the suggestions are applicable to MT analysis. Therefore, following Kageura (Kageura, 2002) and his theory of dynamics of term formation (1) we consider that a greater number of new terms are formed on the basis of already existing terms. However, a study on MT's formation patterns should be placed in a diachronic framework (2) since models are vulnerable to certain dynamic tendencies like historical possibilities of "neology and circumlocution to create new lexical resources" (Wüster, 1985).

Several studies confirm that semantic models of terminology are at odds with each other. Since the present paper focuses on MT systematization and elaboration of translation strategies, the chosen model, must bring to the foreground salient characteristics of the term as a criterion that ensures adequate translation in case of inter-language transformations. Thus, considering dynamic nature of MT, it seems most reasonable to analyze its semantic structure in terms of the Nuclear-Peripheral Theory of Meaning (Alimuradov et.al., 2011) that claims heterogeneity of the term semantic structure which is presented by obligatory and optional components: the nucleus (marked by carrying a major "meaningful load" of the term and its salient characteristics); peripheral area (contains additional semantic information); and auxiliary areas of semantics. Although terminological evidence collected in a particular subject field cannot be applied to terminology in general, principles based on the analysis of a SL terminology still work while applied to the TL terminology of the same subject domain. The Core-Peripheral analysis of MT will help to ensure translation equivalence as it guarantees that core areas bearing salient characteristics are preserved in $\mathrm{TL}$.

\section{2 "Content Interaction" within SFTs}

Particular SFTs are interconnected and interdependent and different types of mutual influence (borrowings, shifts) become obvious when we have a look at the collections of SFTs which serve the needs of similar scientific or professional areas. Mediation is a "discourse-centered practice" (Chernyshenko and Alimuradov, 2013) and the levels which build up the polyphonic structure of this discursive model are characterized by the usage of specific terms that serve as significant and foundational components in establishing participants' positions, introducing options or suggesting compromise. In other words, the role of the terms in the mediation discourse is not limited to the pure representation of the scientific (or, more precisely, professional) knowledge, but seeks to promote effective communication and achievement of the parties' pragmatic goals. Besides, MT's specific sphere of reference provides a basis for defining MT as a terminology that has a clearly applied nature.

Considering that mediation is a part of ADR (Alternative Dispute Resolution) which at the same time belongs to legal discourse, we can presuppose a possibility of mutual term exchange, and borrowings within these terminologies 
(the processes that we will further refer to as "content interaction"). In addition, informal style of mediation sessions and pragmatic orientations of the parties stipulate penetration of specific psychological terms into MT. Forming multiple intersections with related terminologies, MT does not only borrow terminological units, but also behaves as content "donor". The Figure 1 below shows terminologies most relevant to MT and their content intersections.

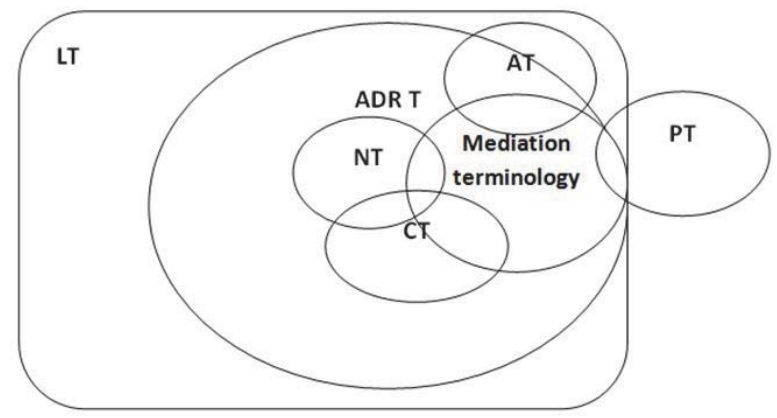

Figure 1 - Content interaction between MT and other related terminologies*; *ADR T - ADR Terminology; NT Negotiation Terminology; CT - Conciliation Terminology; AT - Arbitration Terminology; LT - Legal Terminology; PT Psychological Terminology

ADR terminology is a complex system that unites terminologies which ensure the functioning of the four most common out-of-court practices - mediation, arbitration, negotiation, and conciliation. Although these procedures are similar, they do not only use different methods (e.g. arbitrator makes the final decision himself but mediator just facilitates negotiations) but also specific terms (NADRAC, 2002). Since ADR in general and mediation in particular are considered in the legal context, general legal terms are widely used in processes of alternative conflict resolution. Moreover, linguistic requirements for MT, providing its informative quality, resemble the characteristics of legal terminology with some reservations concerning the "stability" of MT. It can be called just relatively stable, primarily because the procedure is relatively new and, consequently, its terminology is evolving, being replenished with new elements. Besides, the idea of abandoning traditional terms used in the legal field, can be traced quite clearly in MT. Despite the fact that any mediation decision is made on the basis of mutual consent but not a regulatory act, it is assumed that the terms fixing agreements between the parties, should be as "accessible" as possible. It can be concluded that the terms that serve as "building blocks" for the deployment of the mediation discourse are primarily words and phrases known to most people who decide to enter mediation.

\subsection{Objectives}

The objectives of this study were to: 1) analyze source language MT at the structural and semantic levels; 2 ) suggest directions for systematization of Russian MT based on the analyzed data 3) suggest strategies for translating English MT into Russian.

\section{Method}

\subsection{Data Collection}

As we have mentioned in the introduction, the main obstacle to MT systematization is that MT exists in a form of short glossaries but not as a fixed SFT. Thus, the first objective of the researchers involved in the project was to collect data from all the recourses possible. Mediation specialists who took part in the study collected 903 items of terminological evidence used in the course of real mediation sessions; the other 1360 units were extracted from the mediation text corpus that consists of 6254 articles, 3598 mediation documents as well as 3403 publications and reports by mediation associations, advisory councils which cover standards for mediation. This study uses terminological data that was issued from 1999-2014 covering most significant periods of mediation evolution and expansion. For more convenient term extraction, linguists have created an electronic MT database with the following parameters: field of use (general/divorce 
mediation/ custody mediation/medical mediation etc.), term-formation type number of components, eponymy, definition, semantic type of terms, context samples, motivation, abbreviation, synonyms, antonyms, hypernyms and hyponyms (Table 1).

Table 1 - Fragment of MT database

\begin{tabular}{|c|c|c|c|c|c|c|}
\hline Term & Abbreviation & Field of Use & $\begin{array}{l}\text { Term-formation } \\
\text { Type }\end{array}$ & \begin{tabular}{|c|} 
Number of \\
Components
\end{tabular} & Semantic Types of Terms & Motivation \\
\hline Collaborative law & - & general & word-combination & 2 & Uninuclear with periphery & + \\
\hline Conflict resolution & - & general & word-combination & 2 & Uninuclear with periphery & + \\
\hline Court-ordered mediation & - & general & word-combination & 3 & Uninuclear with periphery & + \\
\hline Dispute resolution & - & general & word-combination & 2 & Uninuclear with periphery & + \\
\hline Mediator & - & general & Affixation (Suf.) & 1 & Uninuclear & + \\
\hline $\begin{array}{l}\text { Mediation Information and } \\
\text { Assessment Meetings }\end{array}$ & MIAM & general & word-combination & 4 & $\begin{array}{l}\text { Uninuclear with periphery } \\
\text { and additional components }\end{array}$ & + \\
\hline Restorative justice & - & general & word-combination & 2 & Uninuclear with periphery & $\begin{array}{c}\text { false } \\
\text { motivation }\end{array}$ \\
\hline
\end{tabular}

\subsection{Data analysis}

Used methodology meets the purpose of the present study that is twofold: to prepare a systematized description of MT by considering it in terms of semantics and structure and suggest strategies for translating English MT into Russian. Therefore, three classical stages of linguistic research (collection, analysis and explanation) are put forward. Considering that SFTs use a range of term-formation patterns, the aim of the linguists was to track most actively used models, comparing the number of productive models from the general language and those functioning mainly in LSP. Structural analysis performed on 2263 mediation terms aimed at building all the possible models of term-formation and component structure within MT.

MT was also subjected to the Nuclear-Peripheral analysis (see 2.1). In fact, most of the crucial controversies in term translation are due to the shift of the original nuclear meaning in TL or misinterpretation of the peripheral meaning. Although semantic structure of English terms and their Russian variants is not always identical and may vary depending on the diverse TL sources chosen for translation, central semantic component of the nuclear area must be always preserved in $\mathrm{TL}$ in order to provide adequate equivalents. Hence, some of the mediation terms translated into Russian copy semantic pattern of a source term (1)

(1) Eng. Transformative periphery + mediation $^{\text {nucleus }}$ (uninuclear with periphery)

Rus. Преобразующая ${ }^{\text {periphery }}+$ медиация ${ }^{\text {nucleus }}$ (uninuclear with periphery) while some models undergo transformations (extension of the periphery/additional components), however, preserving the nucleus (2).

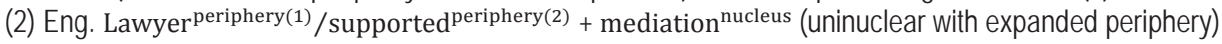

Rus. Медиация ${ }^{\text {nucleus }}+c^{\text {additional component }}+$ участиием ${ }^{\text {periphery(2) }} /$ адвоката ${ }^{\text {periphery(1) }}$ (uninuclear with expanded periphery and additional component)

This principle laid the basis for the MT Translation Project - an effort to provide understandable Russian terms which represent concepts existing within mediation practice. The overall approach is similar to that used by a successful Danish term translation project SUNDTERM (Høy, 2006) and implies close collaboration between subject matter experts and linguists/terminologists. According to the International Information Centre for Terminology, "interdisciplinary collaboration is crucial in terminology work" (Infoterm, 2005) Translation based only on linguistic analysis may provide terms which fail to reflect the concept and as a result will not be used in LSP communication (Høy, 2006).

The participants involved in MT Translation Project (linguists, translators and mediation specialists) performed strictly prescribed functions: development of linguistic principles of the research (linguist), translation of terms and translation review (translators), approval or rejection of translated terms depending on adequate/inadequate reflection of the existing concepts (mediation specialists). The web-based process was held in closed online chat-rooms. While developing the suitable work flow mechanism for MT Translation Project we referred to some multistep-translation principles suggested by SUNDTERM developers (with some reservations concerning the number of subject matter specialists).

The work flow (Figure 2) of MT Translation Project:

1) Linguist distributes terms from MT database among translators. 
2) Translator 1 sends a translated term to Translator 2 for a review. If a term is rejected, it returns to Translator 1 for revision. If a term is approved, it is sent to Mediation Specialist 1.

3) Mediation specialist may either approve or reject the term sending it back to Translator 2. Approved terms come to MT data collection where they are distributed according to the field of use they belong to (general, custody mediation etc.). Linguist who is distributing approved terms checks once again that the nuclear semantic component is preserved in the translated term.

4) In case of doubt, terms are sent to subject matter expert 2 who reviews them and gives a consultation.

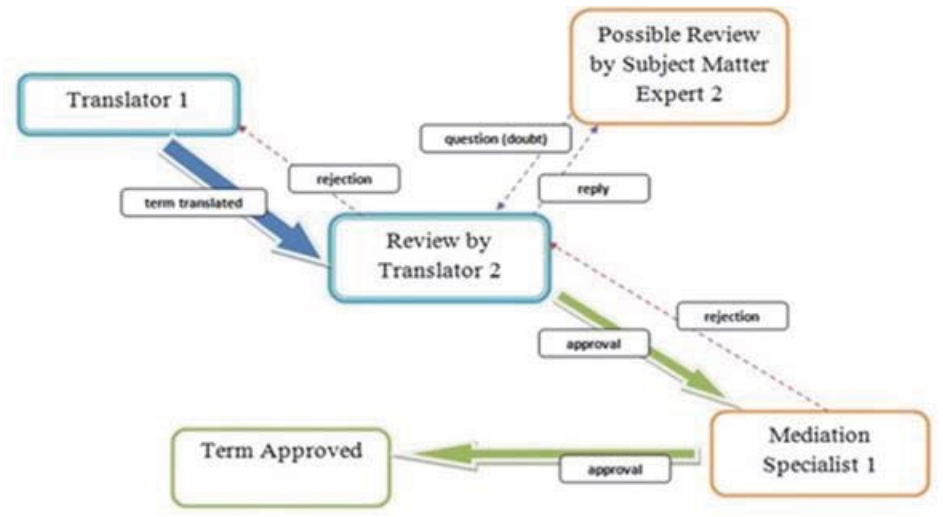

Figure 1 - Work Flow of the MT Translation Project

During the translation process a set of formal, functional and descriptive techniques were employed in most diverse variants to ensure adequate representation of mediation concepts. It allowed describing and comparing both TL- and SLoriented strategies (Harvey, 2002) that seem to be most appropriate for translating particular types of mediation terms.

\section{Results and Discussion}

\subsection{Results from Structural and Semantic Analysis. Systematization of MT}

Systematization of terminologies is based on a set of criteria which are, in fact, structural and semantic requirements for the terms of a particular SFT. All the structural models of MT were tracked down and subjected to a quantitative analysis to decide which of them can be accepted as structural standards. Among the parameters taken into account were: frequency of models' use (Alimuradov et al., 2011); ability to act as productive patterns for building new terms (Ibid.). Besides, structural analysis of English MT allowed drawing some general conclusions about term-formation tendencies within English MT which were further applied for elaboration of systematization principles of Russian MT:

1) Mono-component terms (14.32\%) appear to be a minority while quantitative preference is given to multicomponent terms (85.68\%) with the complex structure that does not compromise their understandability and psychological acceptability. Prolonged definitional constructions (5-6 components) are not typical for MT, though.

2) The analysis indicated that terminological units from other SFTs in $19.4 \%$ of cases are used as building material for two- and three-component mediation terms. Predominantly these are terms (or parts of complex terms) presenting psychological concepts (cognitive, escalation etc.) and legal terms which get into the structure of mediation multi-component terms as attributes.

The overall analysis showed that syntactic term-formation (73.6\%) dominates over morphological $(7.02 \%)$ and morphosyntactic (19.31\%) term-formation (see Table 2). The most productive structural models are Adj.+N (14\%), N+N (9.5\%) and Participle II+N (8.9\%). In 39.5\% of all the cases formation of multi-word combinations is due to the "extension" of a term of the previous level. High productivity of certain terms allows them to form "nests" that number dozens of multicomponent terms.

Only $6.5 \%$ of the mediation terms are derivatives. (67\%) of all the abbreviations used in MT (4.63\%) are acronyms 
and function as independent words. Terms formed by specialization of meaning (2.2\%) are more common for written mediation; neology has not been traced.

Table 2 - Structural Models of English MT

\begin{tabular}{lccl}
\hline Structural Models of English MT & Number of Terms & Percentage & Productiveness \\
\hline Morphological term-formation & 159 & 7.02 & \\
Derivation & 148 & 6.50 & \\
Pref.+N & 43 & 1.90 & low \\
$\mathrm{N}+$ Suf. & 54 & 2.38 & low \\
Pref.+N+Suf. & 51 & 0.92 & low \\
Conversion & 11 & 0.48 & \\
$\mathrm{~N}$ to V & 0 & 0 & \\
V to N & 11 & 0.48 & critically low \\
Syntactic term-formation & 1667 & 73.6 & \\
$\mathrm{~N}+\mathrm{N}$ & 215 & 9.50 & high \\
$\mathrm{N}+$ Participle I & 138 & 6.09 & high \\
Adj.+N & 317 & 14.0 & high \\
Participle II+N & 202 & 8.90 & high \\
Adj. +N+Participle I & 105 & 4.63 & relatively high \\
Adj. + Participle I & 58 & 2.56 & low \\
$\mathrm{N}+\mathrm{N}+\mathrm{N}$ & 109 & 4.81 & relatively high \\
$\mathrm{N}+\mathrm{N}+$ Participle I & 97 & 4.20 & relatively high \\
$\mathrm{N}+$ Participle I+ N & 45 & 2.03 & low \\
Participle II+N+N $+\mathrm{N}$ & 107 & 4.72 & relatively high \\
Adj.+N+N & 138 & 6.09 & relatively high \\
$\mathrm{N}+\mathrm{N}+\mathrm{N}+\mathrm{N}$ & 38 & 1.67 & low \\
Participle II +N+N+N & 48 & 2.12 & low \\
Morphosyntactic term-formation & 437 & 19.31 & \\
Compound & 102 & 4.50 & relatively high \\
Adj.+Compound & 113 & 4.99 & relatively high \\
Adj.+Compound +N & 103 & 4.55 & relatively high \\
Blending & 2 & 0.08 & critically low \\
Ellipse & 6 & 0.26 & critically low \\
Abbreviation & 105 & 4.63 & relatively high \\
Clipping & 6 & 0.26 & critically low \\
Back-formation & 0 & 0 & \\
Other & & & \\
Neology & 0 & 0 & \\
Specialization & 50 & 2.20 & low \\
\hline Total & 2263 & 100.00 & \\
\hline
\end{tabular}

The semantic analysis showed that a greater part of mediation terms (75.43) are uninuclear terms with periphery with the nuclear meaning presented by a noun (98.7\%) and periphery expressed by adjectives (36.82\%) and Participle I (12.32\%) and Participle II (6.84\%). The second position is occupied by uninuclear terms (14.9\%) which designate abstract concepts, types of sessions and names of participants while the number binuclear terminological $(7.1 \%)$ units is extremely small (comparing to fundamental terminologies) (Table 3).

Table 3 - Semantic Models of English MT

\begin{tabular}{lc}
\hline Semantic Models of MT & Percentage \\
\hline Uninuclear & 14.90 \\
Uninuclear with periphery & 75.43 \\
Uninuclear with periphery and additional components & 2.57 \\
Binuclear & 7.10 \\
\hline Total & 100.00 \\
\hline
\end{tabular}

Terms within MT are linked to each other via relations like antonymy, synonymy, hyperonymy. However, the semantic 
analysis of English MT also indicated some negative synonymic tendencies which are regarded as obstacles to MT systematization. Equivalence and partial equivalence of the terms within one terminological system must be regarded with different degree of desirability (Streiter, 2006). Some of MT terms make synonymic pairs which are formally different words (or combinations) with identical meanings (e.g. there are at least 7 terms used to denote the position of mediator). It significantly degrades the quality of information and causes difficulties in professional communication. The translation of English MT (see 4.2) into Russian also proved the assumption that the problem of excessive synonymy within MT is international.

Practical suggestions for systematization of MT may be described as follows:

1) The identified generic relations between lexico-semantic groups of English MT should be also fixed in Russian MT.

2) Polysemy traced in $6 \%$ of the analyzed terms should be eliminated as it challenges psychological acceptability of the term.

3) In case of synonymic diversity, one of the synonymous terms should be chosen to represent a concept. Preference should be given to most understandable and frequently used terms.

\subsection{Translation Strategies}

MT is used to serve the needs of a new out-of-court procedure that differs substantially from standard sessions in court and had not had analogue in Russia. Therefore, some specific mediation concepts have no equivalents in Russian. Employing TL- and SL-oriented strategies aimed at finding functional or partial functional equivalents of English mediation terms in Russian. The MT Translation Project focused on choosing strategies which should be used for translating a particular group of mediation terms. Our further considerations and suggestions are based on the results which were discovered after the translation of 2263 terms divided into thematic groups. The chosen groups comprises four types of terms: 1) the terms defining abstract concepts (including conflict issues, claims, types of processes); 2) the terms defining peoples' professions/positions within mediation; 3 ) the terms defining pragmatic strategies used in mediation; 4) the terms defining psychological states.

Translation techniques employed for providing Russian variants of English MT included both direct translation techniques (calques, borrowing, literal translation) and oblique techniques (transposition, modulation, reformulation or equivalence and adaptation). (Table 4)

Table 4 - Translation Techniques used for Translating English MT into Russian

\begin{tabular}{lc}
\hline Translation Techniques & Percentage \\
\hline Direct translation techniques & \\
Borrowing & 3.13 \\
Calque & 53.30 \\
Literal translation & 5.68 \\
Oblique translation techniques & \\
Transposition & 0.58 \\
Modulation & 1.50 \\
Reformulation & 9.10 \\
Adaptation & 2.14 \\
Equivalence & 24.62 \\
\hline Total & 100 \\
\hline
\end{tabular}

The results of the study suggest that SL-oriented strategy seeks to preserve the structural elements and conceptual content of the SL sometimes even transposing the original linguistic form into the target language. SL-oriented strategy was employed by the translation of (62.11\%) of mediation terms through such direct translation techniques as borrowing, calques and literal translation. TL-oriented strategy focused on assimilation of original terms into TL was used when direct translation was impossible and structural and semantic elements of the target language were to be altered.

The detailed analysis of the MT translation shows that SL-oriented strategy is prevalent since most of the terms are translated into Russian by calques (53.3\%). It should be emphasized that past inconsistencies in MT translation which compromised its acceptability were caused by the following erroneous translation tendency. MT was considered in legal aspect and assessed as a special domain in legal terminology. As a result TL-oriented strategies (which are usually used for translating legal terms) were applied to mediation. There were multiple attempts to find absolute Russian equivalences 
for English terms in legal vocabularies which resulted in the selection of confusing terms which did not represent actual mediation concepts.

We suggest that every mediation term must be assessed individually in order to decide which of the strategies is preferable for its translation; however, strict TL- orientation to MT translation seems to be undesirable as it often fails to reflect concepts in question.

\section{Conclusion}

This study is just the first step to systematization and standardization of MT, which was undertaken to identify the boundaries of this terminological system, to track down and fix most productive structural models that can be considered as standards and to understand what means are used to represent the nuclear semantics of mediation concepts. The MT translation project showed that translation problems concerning mediation terms are due to incorrect interpretation of MT's nature and erroneous conviction that mediation terms are, in fact, legal terms used out of court.

The study analyzed 2263 units of terminological evidence collected from overall 9852 publications and 3 mediation specialists. The results showed that a larger part of mediation terms are multi-component terms. Uninuclear-peripheral models of term semantics appeared to be most typical of MT. Further work on systematization of MT should address the problem of excessive synonymy and polysemy which leads to difficulties in term understand.

Researches on both Russian and English MT have great future prospects. There is a need for definition analysis and elaboration of MT's frame model; terminological oppositions and motivational models. A more distant perspective of the present study is compiling of the electronic Russian MT dictionary.

\section{Acknowledgements}

The authors express their gratitude to the Russian Foundation for Humanitarian Research (project \#15-04-00392 Systematization and Standardization of Mediation Terminology in Russia) that financially supported the study.

\section{References}

Kobysheva, E., \& Golovchenko, I. (2012). Evropejskij kodeks povedenija mediatorov: Processual'nyj status, jeticheskie objazatel'stva i modeli oplaty uslug mediatorov. Vestnik PGLU, 179-183.

Clark, H. H., \& Brennan, S. E. (1991). Perspectives on socially shared cognition. Washington, DC: American Psychological Association.

Steurs, F. (2004) Comment: The coining of terms and the relationship between general and scientific vocabulary. Terminology Science and Research, Vol 15. Retrieved from http://iitf.fi/cms/component/remository/func-startdown/9/?/temid=108

Rogers, M. (2004) Comment: Looking back to get ahead a historical view of term formation and regulation. Terminology Science and Research, Vol 15. Retrieved from http://iitffi/cms/component/remository/func-startdown/9/?temid=108

Humbley, J. (2009)Accounting for term formation. Terminology Science and Research, Vol 20. Retrieved from http://iitffil/cms/ publications

Høy, A. (2000). Morphological Considerations Concerning the Nationalisation of Medical Terms. Hermes, Journal of Linguistics No. 25.

Kageura, K. (2002). The dynamics of terminology. A descriptive theory of term formation and terminological growth. Amsterdam/ Philadelphia: Benjamin.

Wüster, E. (1985). Einführung in die allgemeine Terminologielehre und terminologische Lexikographie. 2. Aufl. Copenhagen.

Alimuradov, O., Latu, M., \& Pazduev, A. (2011). Osobennosti struktury i funkcionirovanija otraslevyh terminosistem (na primere terminosistemy nanotehnologij) (p. 99). Pyatigorsk: Sneg.

Chernyshenko, A., \& Alimuradov, O. (2013). Linguistic Parameters of the Mediation Discourse. Middle East Journal of Scientific Research, 1092-1096.

Høy, A. (2006). Coming to terms with shomed terms: linguistic and terminological issues related to the translation into Danish. Terminology Science and Research, Vol 17. Retrieved from http://iitf.fi/cms/publications

Infoterm. (2005). Guidelines for Terminology Policies, UNESCO, Paris (CI-2005/WS4).

Harvey, M. (2002). What's so Special about Legal Translation?. Meta:Translators' Journal. 47(2). Retrieved from http://www.erudit.org/ revue/meta/2002/v47/n2/008007ar.pdf 